\title{
In vitro antimicrobial activity of a novel compound, Mul-1867, against clinically important bacteria
}

\author{
George Tetz $^{1 *}$ and Victor Tetz ${ }^{2}$
}

\begin{abstract}
Background: The antimicrobial activity of Mul-1867, a novel synthetic compound, was tested against 18 bacterial strains, including clinical isolates and reference strains from culture collections.

Methods: The minimal inhibitory concentration (MICs) and minimal bactericidal concentration (MBCs) were determined by using the broth macrodilution method. The kinetics of the inhibitory effects of Mul-1867 against biofilm-growing microorganisms was assessed at time-kill test in vitro against 48-h-old biofilms of Staphylococcus aureus and Escherichia coli. Transmission electron microscopy analyses was conducted to examine cell disruption.

Results: A comparative assessment of the antimicrobial activities of Mul-1867 and chlorhexidine digluconate (CHG), used as a control antimicrobial, indicated that Mul-1867 was significantly more effective as a disinfectant than CHG. Mul-1867 showed potent antimicrobial activities against all the tested bacteria (MIC: $0.03-0.5 \mu \mathrm{g} / \mathrm{mL}$ ). Furthermore, $\mathrm{MBC} / \mathrm{MIC}$ ratio of Mul-1867 for all tested strains was less than or equal to 4 . Time-kill studies showed that treatment with Mul-1867 (0.05-2 \%) reduced bacterial numbers by 2.8-4.8 log 10 colony forming units (CFU)/mL within 15-60 s. Bactericidal activity of Mul-1867 was confirmed by morphological changes revealed by TEM suggested that the killing of bacteria was the result of membrane disruption.
\end{abstract}

Conclusion: Overall, these data indicated that Mul-1867 may be a promising antimicrobial for the treatment and prevention of human infections.

Keywords: Bactericidal, Biofilms, Resistant, Time-kill, Chlorhexidine gluconate

\section{Background}

Microbial infections are one of the main causes of morbidity and mortality. Infectious disease treatments are associated with challenges including increasing antimicrobial resistance, drug cytotoxicity, and limited drug spectrum and these difficulties have instigated novel antimicrobial drug development [1-3]. Antibiotic and antiseptic resistance have partly emerged by the prevalence of bacteria in the form of biofilms, which enable microorganisms to survive antibiotic concentrations that are 1000 times higher than the minimal inhibitory concentration (MIC) [4-6]. Previous studies have attributed the high antibiotic tolerance of biofilms to a lipid-composed

\footnotetext{
* Correspondence: georgetets@gmail.com

${ }^{1} \mathrm{TGV}$-Therapeutics, Institute of Human Microbiology, LLC, 303 5th avenue, suite 2012, New York, NY 10016, USA

Full list of author information is available at the end of the article
}

film that is present on the outer surface and due to the presence of extracellular polymeric substances inside microbial community [7, 8]. Biofilms have also been associated with a variety of human infections and are known to be poor responders to antibiotic and antiseptic therapy [9-11].

Topical antimicrobial agents are routinely used in various branches of medicine such as dentistry, otolaryngology, surgery and gynecology [12-16]. They are also used to reduce nosocomial infections and are particularly useful in preventing infections in intensive care unit patients [17-19]. Chlorhexidine gluconate (CHG) is one of the most widely used antimicrobial agents due to its broad spectrum of antimicrobial action and compatibility with several types of materials [20-23]. The above-mentioned properties of CHG have enabled its incorporation in numerous pharmaceutical and medical devices [24, 25]. 
Furthermore, the emergence of chlorhexidine-resistant microorganisms, for example Klebsiella pneumoniae and Staphylococcus aureus have also posed treatment challenges $[26,27]$. Thus, there is a critical need for the development of new antimicrobials that have a broad-spectrum of antimicrobial activity and that can be effectively used to treat resistant bacteria.

In this study, we describe a potential new antimicrobial compound called Mul-1867 [poly-N1-hydrazino(imino)methyl-1,6-hexanediamine; Fig. 1].

The objective of this study was to assess the in vitro antibacterial activity of Mul-1867. Furthermore, the comparative antimicrobial efficacies of Mul-1867 and CHG against established 48-h-old biofilms were also assessed.

\section{Methods}

\section{Antimicrobial agents}

Mul-1867 was synthesized in TGV-Laboratories Inc. (NJ, USA). CHG solution (20\% in $\mathrm{H}_{2} \mathrm{O}$ ) was obtained from Sigma Chemical Co. (St. Louis, Mo.). Mul-1867 and CHG were diluted with sterile distilled water on the day of use.

\section{Bacterial strains}

Bacillus cereus VT-289, Enterococcus faecalis VT-72, E. faecalis VT-693, Escherischia coli VT-1402, K.pneumoniae VT-1367, Neisseria subflava VT-455, Pseudomonas aeruginosa VT-177, Salmonella enterica VT-191, S. aureus MSSA VT 961, S. aureus MRSA VT -234, Streptococcus epidermidis VT-432, S. mitis VT-842, and S. pyogenes VT 59, S. epidermidis VT 908 were obtained from a private collection (provided by Dr. V. Tetz, Institute Of Human Microbiology, LLC). Control strains included E. faecalis ATCC 29212, E. coli ATCC 25922, P. aeruginosa ATCC 27853, and S. aureus ATCC 29213 and were purchased from American Type Culture Collection (ATCC). All bacterial strains were subcultured from freezer stocks onto brain heart infusion agar plates (BHI; Difco, Detroit, MI, USA) and incubated at $37{ }^{\circ} \mathrm{C}$ overnight. All subsequent liquid subcultures were derived from colonies isolated from these plates and were grown in LuriaBertani broth medium (LB, Oxoid).

\section{Antimicrobial susceptibility of planktonic bacteria}

The MICs and minimal bactericidal concentrations (MBCs) for antimicrobials were determined by using the broth macrodilution method in accordance with the Clinical and Laboratory Standards Institute guidelines $[28,29]$. A standard inoculum of $5 \times 10^{5} \mathrm{CFU} / \mathrm{mL}$ was used. Serial 2-fold dilutions of the antimicrobials were prepared in cation-adjusted Mueller-Hinton broth. The MIC was defined as the lowest concentration of antibiotic that completely inhibited visible growth. The MBC was defined as the lowest antimicrobial concentration that killed $\geq 99.9 \%$ of the initial bacterial count $(\geq 3$ $\log 10 \mathrm{CFU} / \mathrm{mL})$ in $24 \mathrm{~h}$.

\section{Kinetics of Mul-1867 and CHG activity against biofilms}

To determine the minimum concentration and exposure time required by Mul-1867 and CHG to kill biofilms, we performed a time-kill test in vitro and assessed the activity of serially diluted Mul-1867 and CHG against the biofilms of $S$. aureus ATCC 29213 and E. coli ATCC 25922. This method was developed for determining MIC of antibiotics against planktonic growing cells by Ernst et al. [30]. We used a modified protocol of this method to study the antimicrobial activities of Mul-1867 and CHG against preformed biofilms. Briefly, all bacterial cultures were grown overnight as liquid cultures and $200 \mu \mathrm{L}$ inoculum $\left(5 \times 10^{5} \mathrm{CFU} / \mathrm{mL}\right)$ for each strain was transferred to a 96-well microtiter plates (Sarstedt, Numbrecht, Germany). The plates were then incubated for $48 \mathrm{~h}$ at $37{ }^{\circ} \mathrm{C}$. The wells proximal to the plate frame were filled with medium only and were used as negative controls for growth. After incubation, the growth medium was removed from the wells without disrupting the integrity of the biofilms. The formed biofilms were then gently washed three times with PBS to remove nonadherent cells. Next, $200 \mu \mathrm{L}$ of Mul-1867 or CHG diluted in sterile distilled water were added in the appropriate wells for 15,30 , or $60 \mathrm{~s}$. Untreated biofilms were used as negative controls for each isolate at each time point. After the exposure, well contents were aspirated again and to prevent antimicrobial carry-over each well was washed three times with deionized water. Biofilms were scraped thoroughly, with particular attention to

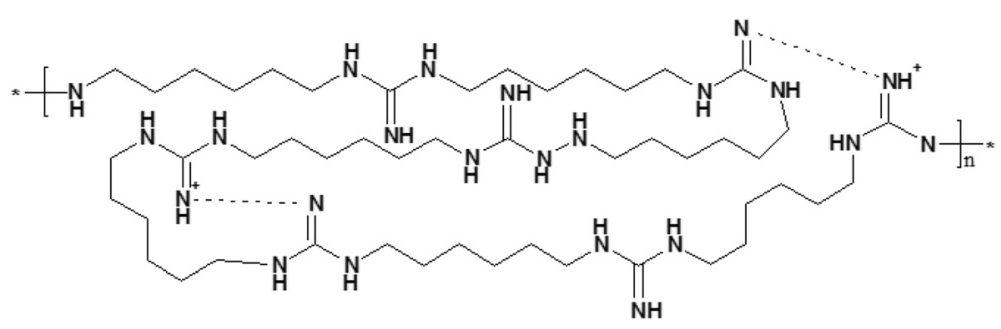

Fig. 1 Chemical structure of Mul-1867, $n=1-20$ 
well edges. The well contents were aspirated again, then placed in $1 \mathrm{~mL}$ of PBS and the total CFU number was determined by serial dilution method and plating on appropriate media. Data were converted to a $\log 10$ scale and compared to $1 \times 10^{8} \mathrm{CFU}$ untreated 48-h-old biofilms. All assays included at minimum 2 replicates and were repeated in 3 independent experiments.

\section{Transmission electron microscopy}

Transmission electron microscopy analyses was conducted to examine cell disruption. The assay was performed using planktonic growing $S$. aureus ATCC 29213. Bacteria were centrifuged $3000 \mathrm{~g}$ (Eppendorf 5415 C centrifuge; Eppendorf Geratgebau GmbH, Hamburg, Germany) and suspended in isotonic phosphate buffer (0.15 M, pH 7.2). Mul-1867 was added to the bacterial suspension to a final concentration of $0.5 \%$. Tubes were shacked for $30 \mathrm{~s}$ at $22^{\circ} \mathrm{C}$ and bacteria were harvested by $10 \mathrm{~min}$ of centrifugation at $3000 \mathrm{~g}$. After treatment, cells were observed under a transmitting electron microscope (Carl Zeiss, LIBRA 120) at $80 \mathrm{kV}[31,32]$.

\section{Evaluation of Mul-1867 effect on membrane integrity}

The assay was performed using planktonic growing $S$. aureus ATCC 29213 and E. coli ATCC 25922. Mul-1867 was added at final concentration $0.5 \%$ to a standard inoculum of $5 \times 10^{7} \mathrm{CFU} / \mathrm{mL}$. Tubes were shacked for $30 \mathrm{~s}$ at $22^{\circ} \mathrm{C}$ and bacteria were harvested by $10 \mathrm{~min}$ of centrifugation at $3000 \mathrm{~g}$ (Eppendorf $5415 \mathrm{C}$ centrifuge). DNA was extracted from the supernatant solution with QIAamp DNA Mini Kit (Qiagen, GmbH), following the manufacturer's instructions. DNA amount was determined by optical density at $260 \mathrm{~nm}$ (OD260) using an Eppendorf BioPhotometer 6131 (Hamburg, Germany). To control the purity of the DNA, only samples with an OD260/OD280 ratio of 1.8-2.0 were used for subsequent analysis. A background value of OD at $320 \mathrm{~nm}$ was subtracted from the measured values of OD260 and OD280. Measurements were conducted at room temperature.

\section{Statistical analysis}

All experiments were performed in triplicates. Results are provided as mean \pm standard deviation. All statistical analyses were performed using the statistics package Statistica for Windows (version 5.0). A $p$-value of $<0.05$ was considered statistically significant.

\section{Results}

\section{Antibacterial activity}

The MICs and MBCs of Mul-1867 against 18 bacterial strains are shown in Table 1.

Mul-1867 inhibited the growth of all the microorganisms tested, with MIC values ranging from 0.03 to
Table 1 In vitro antibacterial activity of Mul-1867

\begin{tabular}{|c|c|c|c|c|}
\hline \multirow[t]{2}{*}{ Organism } & \multicolumn{2}{|c|}{ Mul-1867 (mg/L) } & \multicolumn{2}{|c|}{$\mathrm{CHG}(\mathrm{mg} / \mathrm{L})$} \\
\hline & $\overline{M I C}$ & $\mathrm{MBC}$ & $\mathrm{MIC}$ & $\mathrm{MBC}$ \\
\hline \multicolumn{5}{|l|}{ Gram-positive bacteria } \\
\hline B. cereus VT-289 & 0.5 & 2 & 1.0 & 2.0 \\
\hline E. faecalis ATCC 29212 & 0.03 & 0.06 & 2.0 & 8.0 \\
\hline E. faecalis VT-72 & 0.06 & 0.125 & 4.0 & 16.0 \\
\hline E. faecalis VT-693 & 0.06 & 0.06 & 2.0 & 16.0 \\
\hline S. aureus ATCC 29213 & 0.125 & 0.15 & 2.0 & 2.0 \\
\hline S. aureus MSSA VT-961 & 0.06 & 0.125 & 2.0 & 2.0 \\
\hline S. aureus MRSA VT-234 & 0.06 & 0.125 & 4.0 & 4.0 \\
\hline S. epidermidis VT-432 & 0.06 & 0.125 & 2.0 & 16.0 \\
\hline S. epidermidis VT 908 & 0.25 & 0.5 & 2.0 & 16.0 \\
\hline S. mitis VT-842 & 0.06 & 0.06 & 4.0 & 64.0 \\
\hline S. pyogenes VT 59 & 0.125 & 0.125 & 8.0 & 16.0 \\
\hline \multicolumn{5}{|l|}{ Gram-negative bacteria } \\
\hline E. coli ATCC 25922 & 0.25 & 0.25 & 2.0 & 16.0 \\
\hline E. coli VT-1402 & 0.06 & 0.06 & 16.0 & 32.0 \\
\hline K. pneumoniae VT-1367 & 0.125 & 0.25 & 32.0 & 32.0 \\
\hline N. subflava VT-455 & 0.125 & 0.25 & 8.0 & 8.0 \\
\hline P. aeruginosae ATCC 27853 & 1.0 & 1.0 & 32.0 & 64.0 \\
\hline P. aeruginosae VT-177 & 0.125 & 0.25 & 32.0 & 32.0 \\
\hline S. enterica VT-191 & 0.5 & 2 & 16.0 & 32.0 \\
\hline
\end{tabular}

$0.5 \mathrm{mg} / \mathrm{L}$. The MIC values of Mul-1867 against bacteria were considerably lower than those of CHG. Notably, Mul-1867 antibacterial activity was 2 to 256 times higher than that of $\mathrm{CHG}$ which MIC values ranging from 1 to $32 \mathrm{mg} / \mathrm{L}$. The most resistant test organisms, B. cereus and $S$. enterica, were killed by $2 \mathrm{mg} / \mathrm{L}$ of Mul-1867. In contrast, list the most resistant organisms to $\mathrm{CHG}$ were K. pneumonia and P.aeruginosa with MIC $32 \mathrm{mg} / \mathrm{L}$. The MBCs values of Mul-1867 were lower than $0.5 \mathrm{mg} / \mathrm{L}$ for 14 strains, and the $\mathrm{MBC}$ values for the other 4 strains ranged from 0.5 to $2 \mathrm{mg} / \mathrm{L}$. After Mul-1867 treatment, the $\mathrm{MBC} / \mathrm{MIC}$ ratios of $86 \%$ microbial strains were $<4$, whereas, those of the remaining $14 \%$ of cultures were 4 . Thus Mul-1867 inhibited bacterial growth of all bacterial strains in a bactericidal manner $(\mathrm{MBC} / \mathrm{MIC}$ ratio $\leq 4)$. After $\mathrm{CHG}$ treatment, the $\mathrm{MBC} / \mathrm{MIC}$ ratios were $<4$ for $60 \%$ strains and the ratios ranged from 4 to 12 for the remaining $40 \%$ strains indicating that $\mathrm{CHG}$ displays bactericidal and bacteriostatic effects. No Mul-1867resistant strain was identified among the clinical isolates.

\section{Kinetics of inhibitory effect of Mul-1867 against bacterial biofilms}

The kinetics of the inhibitory effects of Mul-1867 against biofilm-growing microorganisms are summarized in Fig. $2(p<0.005)$. 


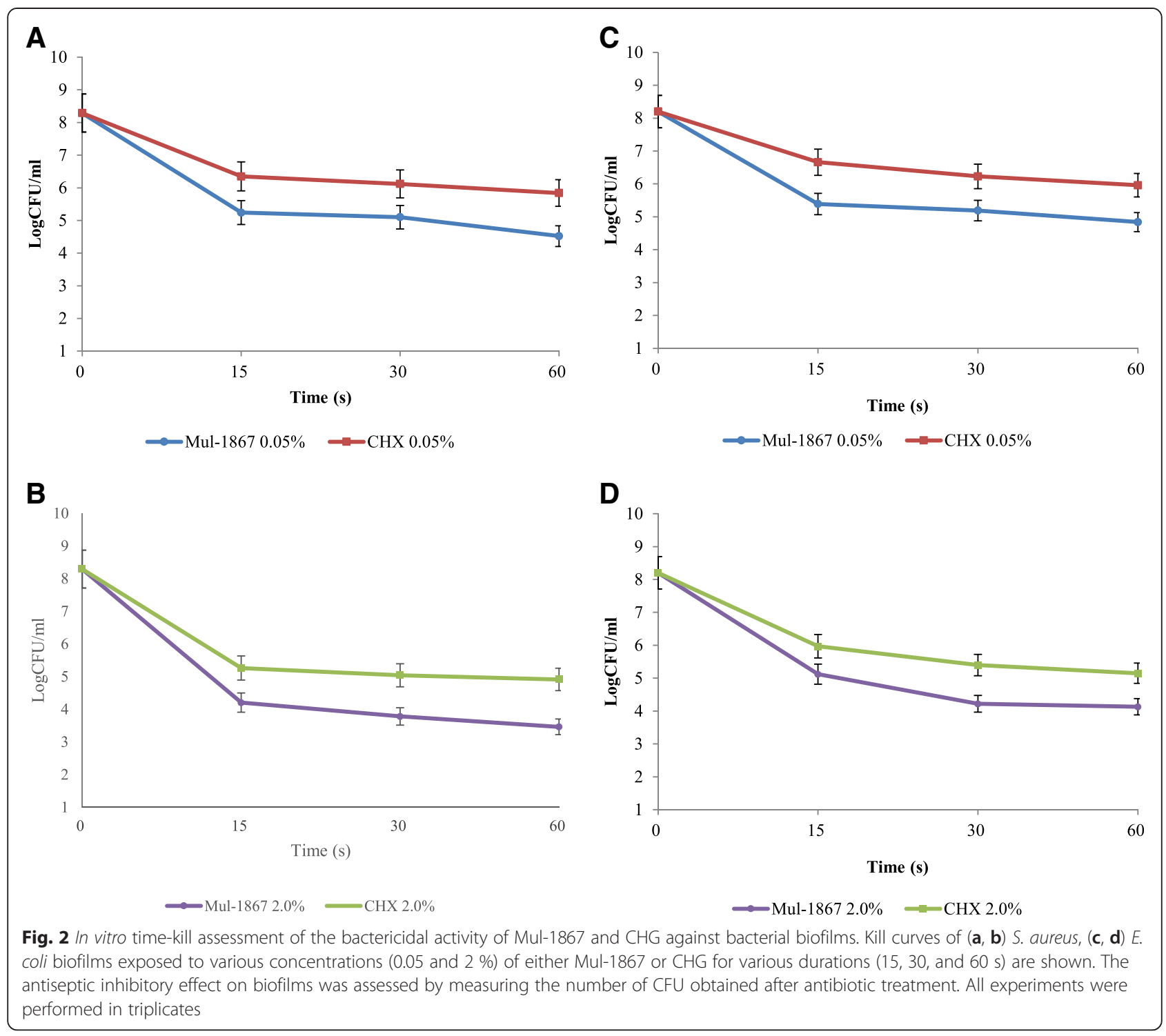

Mul-1867 or CHG displayed a concentration-dependent bactericidal activity against 48-h-old biofilms and exhibited a significant reduction in the number of viable bacteria within biofilms for all periods of exposure. There was a dose-dependent decrease in CFU numbers with increase in antibiotic exposure time for antimicrobials at concentrations of $0.05 \%$ or higher. Our study demonstrated that both antiseptics possess microbicidal activity that can be effective within contact times ranging from 15 to $60 \mathrm{~s}$. The number of viable cells dropped dramatically after $15 \mathrm{~s}$, after which cell death continued at a much slower rate. The bactericidal efficiency of Mul-1867 was higher than that of CHG at the same concentrations. We found that Mul-1867 was approximately up to 20 times more efficient than $\mathrm{CHG}$ at all time points assessed.

\section{Mode of action of Mul-1867 on bacteria}

The untreated S.aureus cells, prepared for TEM micrographs shown a normal cell shape with an undamaged structure of the inner membrane (Fig. 3a). In all cases bacteria appeared to be lysed after Mul-1867 treatment (Fig. 3b).

The images of S.aureus strains show that treated bacteria are collapsed and their cell walls are degraded. The black arrows point out the dead cells with damaged membranes accompanied by the leakage of intracellular components.

Among the indicators of membrane damage, an increased DNA concentration from lysed bacteria in the medium measured spectrophotometry at OD260 was detected (Table 2). 

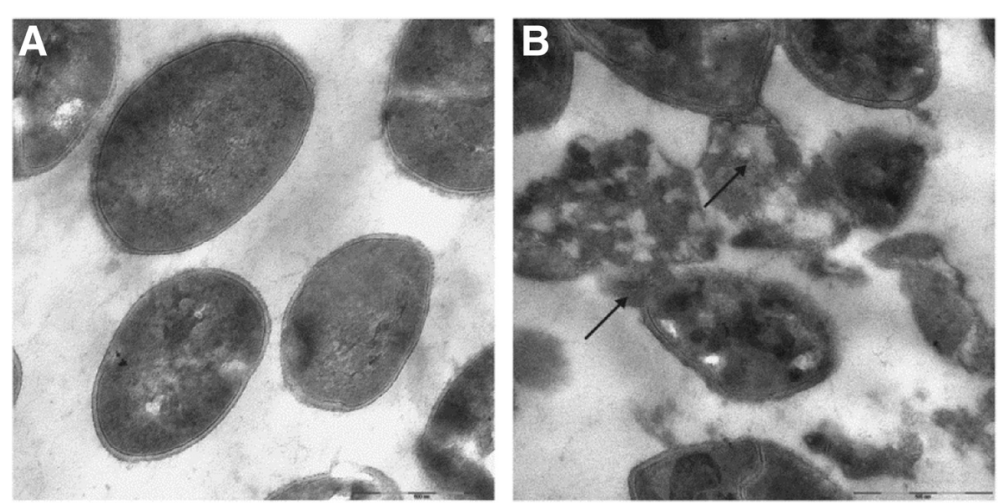

Fig. 3 TEM micrographs of (a) untreated S.aureus (b) incubation with a $0.5 \%$ Mul-1867 for 30 s shows some completely lysed cells

The amount of DNA was increased up to 4.5 times following Mul-1867 treatment for $30 \mathrm{~s}$ compared to untreated cells.

\section{Discussion}

In this study, we examined the antibacterial activitiy of both Mul-1867 and CHG against clinical isolates and reference strains. We have shown that Mul-1867 had broad-spectrum, fast-acting microbicidal activity. It seems to act like other members of the polymeric guanidine family targeting the membrane of the microorganisms [33].

In this study, Mul-1867 was shown to exhibit high antimicrobial activity against all tested strains, including MRSA, which were previously shown to respond poorly to treatment with existing medicines [34, 35]. Importantly, we found that the MICs and MBC values of Mul1867 were less than 4 against a variety of gram-positive bacteria, gram-negative bacteria, indicating that Mul1867 possesses bactericidal activity $[28,36]$. Bactericidal activity of Mul-1867 was confirmed by morphological changes revealed by TEM suggested that the killing of bacteria was the result of membrane disruption. It is confirmed by an increased amount of DNA in the medium $30 \mathrm{~s}$ after Mul-1867 treatment. The molecule of Mul-1867 contains guanidine and hydrazine derivatives. It is known that guanidines groups binds to negatively charged molecules on bacterial surface like carboxyl group $(-\mathrm{COOH})$ of the fatty acid and hydrazine react with carbonyl groups [37, 38]. Binding of guanidine and hydrazine groups to phospholipids, cause bacterial death, followed by disruption of the cell wall and consequent bacteria lysis [39].

Table 2 Effect of Mul-1867 on DNA release from bacteria

\begin{tabular}{lll}
\hline Probe & OD260 & \\
\cline { 2 - 3 } & Untreated & Exposed to $0.5 \% \mathrm{Mul}-1867$ \\
\hline E.coli & 0.058 & 0.238 \\
S.aureus & 0.062 & 0.279 \\
\hline
\end{tabular}

The main limitation of $\mathrm{MIC}$ and $\mathrm{MBC}$ measurements is the inability of the method to determine the rate of microbicidal activity. In our studies, we assessed bacterial viability against Mul-1867 and CHG with time-kill determinations [40]. This method determines the viability of the organisms after contact with antimicrobials for a specified time period and allows us to evaluate the effects of the potential antimicrobial on biofilms, which play a significant role in numerous human diseases and contribute to treatment inefficiency [41-43]. Time-kill studies were performed with 48 -h-old biofilms, and the antimicrobial effects of both Mul-1867 and CHG were determined using two commonly used chlorhexidine concentrations [44, 45]. Time-kill curves of the isolates have shown a clear relationship between the extent of inhibition and the concentrations of Mul-1867 and CHG, indicating that both compounds possessed dosedependent microbicidal activity and could be effective within contact times starting at $15 \mathrm{~s}$. Importantly, Mul1867 was up to 20 times more efficient than CHG at all time points assessed.

\section{Conclusions}

Taken together, our data suggested that Mul-1867 is a promising novel antimicrobial agent that has potent broad-spectrum antibacterial activity against clinically important microorganisms. Further studies will be directed towards development of Mul-1867 as a locally acting antimicrobial.

\section{Competing interests}

The authors declare that there are no competing interest associated with this work.

\section{Authors' contributions}

Conceived and designed the experiments VT GT. Performed the experiments: VT GT. Analyzed the data: VT GT. Contributed reagents/materials/analysis tools: VT GT. Contributed to the writing of the manuscript: GT. Both authors read and approved the final manuscript. 


\section{Acknowledgements}

The authors thank Jeffrey Gelfand, MD, for his helpful comments on the analysis and manuscript.

\section{Author details}

${ }^{1}$ TGV-Therapeutics, Institute of Human Microbiology, LLC, 303 5th avenue, suite 2012, New York, NY 10016, USA. ²Department of Microbiology, Virology, and Immunology, Pavlov First St. Petersburg State Medical University, St. Petersburg, Russia.

\section{Received: 20 July 2015 Accepted: 27 October 2015 Published online: 06 November 2015}

\section{References}

1. Nikaido H. Broad-specificity efflux pumps and their role in multidrug resistance of Gram-negative bacteria. FEMS Microbiol Rev. 2012;36:340-63.

2. Ho J, Tambyah PA, Paterson DL. Multiresistant Gram-negative infections: a global perspective. Curr Opin Infect Dis. 2010;23:546-53.

3. Medzhitov R, Schneider DS, Soares MP. Disease tolerance as a defense strategy. Science. 2012;335:936-41.

4. Tetz GV, Artemenko NK, Tetz W. Effect of DNase and antibiotics on biofilm characteristics. Antimicrob Agents Chemother. 2009:53:1204-9.

5. Bowler LL, Zhanel GG, Ball TB, Saward L. Mature Pseudomonas aeruginosa biofilms prevail compared to young biofilms in the presence of ceftazidime. Antimicrob Agents Chemother. 2012;56:4976-9.

6. Rodríguez-Martínez JM, Pascual A. Antimicrobial resistance in bacteria biofilms. Rev in Med Microb. 2006;17:65-75.

7. Hoiby N, Bjarnsholt T, Givskov M, Molin S, Ciofu O. Antibiotic resistance of bacterial biofilms. Int J Antimicrob Agents. 2010;35:322-32.

8. Tetz W, Korobov VP, Artemenko NK, Lemkina LM, Panjkova NV, Tetz GV. Extracellular phospholipids of isolated bacterial communities. Biofilms. 2004;1:149-55.

9. Tetz W, Tetz GV. Effect of extracellular DNA destruction by DNase I on characteristics of forming biofilms. DNA Cell Biol. 2010;29:399-405

10. Lynch AS, Robertson GT. Bacterial and fungal biofilm infections. Annu Rev Med. 2008;59:415-28.

11. Burmolle M, Thomsen TR, Fazli M, Dige I, Christensen L, Homøe P, et al. Biofilms in chronic infections-a matter of opportunity-monospecies biofilms in multispecies infections. FEMS Immunol Med Microbiol. 2010;59:324-36.

12. Bahna P, Dvorak T, Hanna H, Yasko AW, Hachem R, Raad I. Orthopaedic metal devices coated with a novel antiseptic dye for the prevention of bacterial infections. Int J Antimicrob Agents. 2007;29:593-6.

13. Koban I, Bender CP, Assadian O, Kramer A, Hübner NO. International Society of Chemotherapy Working Group Antiseptics, \& Working Section for Clinical Antiseptic of the German Society for Hospital Hygiene. Clinical use of the antiseptic polihexanide for genital tract infections. Skin pharmacol Physiol. 2012:25:298-304

14. Drosou A, Falabella A, Kirsner RS. Antiseptics on wounds: an area of controversy. Wounds. 2003;15:149-66

15. Okunishi J, Nishihara Y, Maeda S, Ikeda M. In vitro evaluation of the antimicrobial activity of $\mathrm{HM}-242$, a novel antiseptic compound. J Antibiot. 2009:62:489-93.

16. Sheng WH, Ko WJ, Wang JT, Chang SC, Hsueh PR, Luh KT. Evaluation of antiseptic-impregnated central venous catheters for prevention of catheter related infection in intensive care unit patients. Diagn Microbiol Infect Dis. 2000;38:1-5.

17. Edmiston CE, Okoli O, Graham MB, Sinski S, Seabrook GR. Evidence for using chlorhexidine gluconate preoperative cleansing to reduce the risk of surgical site infection. AORN J. 2010;92:509-18.

18. Mimoz O. Chlorhexidine is better than aqueous povidone iodine as skin antiseptic for preventing surgical site infections. Infect Control Hosp Epidemiol. 2012;33:961-2.

19. Ozcaka O, Basoglu OK, Buduneli N, Tasbakan MS, Bacakoglu F, Kinane DF Chlorhexidine decreases the risk of ventilator-associated pneumonia in intensive care unit patients: a randomized clinical trial. J Periodont Res. 2012;47:584-92.

20. Chapman AK, Aucott SW, Milstone AM. Safety of chlorhexidine gluconate used for skin antisepsis in the preterm infant. J Perinatol. 2012;32:4-9.

21. Hidalgo E, Dominguez C. Mechanisms underlying chlorhexidine-induced cytotoxicity. Toxicol In Vitro. 2001;15:271-6.
22. Mangram AJ, Horan TC, Pearson ML, Silver LC, Jarvis WR. Guideline for prevention of surgical site infection. Am J Infect Control. 1999;27:97-134

23. Rosenberg A, Alatary SD, Peterson AF. Safety and efficacy of the antiseptic chlorhexidine gluconate. Surg Gynecol Obstet. 1976;143:789-92.

24. Bhende S, Spangler D. In vitro assessment of chlorhexidine gluconateimpregnated polyurethane foam antimicrobial dressing using zone of inhibition assays. Infect Control Hosp Epidemiol. 2004;25:664-7.

25. Veenstra DL, Saint S, Saha S, Lumley T, Sullivan SD. Efficacy of antisepticimpregnated central venous catheters in preventing catheter-related bloodstream infection: a meta-analysis. JAMA. 1999;281:261-7.

26. Naparstek L, Carmeli Y, Chmelnitsky I, Banin E, Navon-Venezia S. Reduced susceptibility to chlorhexidine among extremely-drug-resistant strains of Klebsiella pneumoniae. J Hosp Infect. 2012:81:15-9.

27. Ho CM, Li CY, Ho MW, Lin CY, Liu SH, Lu JJ. High rate of qaCA-and qacB-positive methicillin-resistant Staphylococcus aureus isolates from chlorhexidineimpregnated catheter-related bloodstream infections. Antimicrob Agents Chemother. 2012:56:5693-7.

28. Clinical and Laboratory Standards Institute. Methods for determining bactericidal activity of antimicrobial agents; approved guideline, M26-A. Wayne, PA: Clinical and Laboratory Standards Institute; 1999.

29. Clinical and Laboratory Standards Institute. Methods for dilution antimicrobial susceptibility tests for bacteria that grow aerobically; approved standard, Clinical and Laboratory Standards Institute document M7-A7. 7th ed. Wayne, PA: Clinical and Laboratory Standards Institute; 2006.

30. Ernst EJ, Klepser ME. Pfaller MA In vitro interaction of fluconazoleand amphotericin B administered sequentially against Candida albicans: effect of concentration and exposure time. Diagn Microbiol Infect Dis. 1998;32:205-10.

31. Pal S, Tak YK, Song JM. Does the antibacterial activity of silver nanoparticles depend on the shape of the nanoparticle? A study of the gram-negative bacterium Escherichia coli. Appl Environ Microbiol. 2007;73:1712-20.

32. Diaz-Visurraga J, Garcia A, Cardenas G. Morphological changes induced in bacteria as evaluated by electron microscopy, Microscopy: Science, Technology, Applications and Education. Badajoz: Formatex; 2010. p. 307-15.

33. Oule MK, Azinwi R, Bernier AM. Polyhexamethylene guanidine hydrochloride-based disinfectant: a novel tool to fight meticillin-resistant Staphylococcus aureus and nosocomial infections. J med microbial. 2008:57:1523-8.

34. Sy A, Srinivasan M. Mascarenhas J Pseudomonas aeruginosa keratitis: outcomes and response to corticosteroid treatment. Invest Ophthalmol Vis Sci. 2012;53:267-72.

35. Sharma A, Rogers C, Rimland D, Stafford C, Satola S, Crispell E, et al. Postdischarge mortality in patients hospitalized with MRSA infection and/or colonization. Epidemiology and infection. 2013;141:1187-98.

36. Plech T, Wujec M, Kosikowska U, Malm A, Kaproń B. Studies on the synthesis and antibacterial activity of 3, 6-disubstituted 1, 2, 4-triazolo [3, 4- $\beta]$ 1, 3, 4-thiadiazoles. Eur J Med Chem. 2012:47:580-4

37. Kim J, Uchiyama T, Carrilho M, Agee K, Mazzoni A, Breschi L, et al. Chlorhexidine binding to mineralized versus demineralized dentin powder. Dental Materials. 2010;26:771-8.

38. Stankovich S, Dikin DA, Piner RD, Kohlhaas KA, Kleinhammes A, Jia Y, et al. Synthesis of graphene-based nanosheets via chemical reduction of exfoliated graphite oxide. Carbon. 2007:45:1558-65.

39. Zhou ZX, Wei DF, Guan Y, Zheng AN, Zhong JJ. Damage of Escherichia coli membrane by bactericidal agent polyhexamethylene guanidine hydrochloride: micrographic evidences. Journal of applied microbiology. 2010;108:898-907.

40. Presterl E, Suchomel M, Eder M, Reichmann S, Lassnigg A, Graninger W, et al. Effects of alcohols, povidone-iodine and hydrogen peroxide on biofilms of Staphylococcus epidermidis. J Antimicrob Chemother. 2007;60:417-20.

41. Mah TFC, O'Toole GA. Mechanisms of biofilm resistance to antimicrobial agents. Trends Microbiol. 2001;9:34-9.

42. Ramage G, Wickes BL, Lopez-Ribot JL. Biofilms of Candida albicans and their associated resistance to antifungal agents. Am Clin Lab. 2001;20:42-4.

43. Hoiby N, Ciofu O, Johansen H, Song Z, Moser C, Jensen P. et al. The clinical impact of bacterial biofilms. Int J Oral Sci. 2011:3:55-65.

44. Gomes BPFA, Ferraz CCR, Berber VB, Teixeira FB, Souza-Filho FJ. In vitro antimicrobial activity of several concentrations of sodium hypochlorite and chlorhexidine gluconate in the elimination of Enterococcus faecalis. Int Endod J. 2001:34:424-8.

45. Carrilho MR, Carvalho RM, Sousa EN, Nicolau J, Breschi L, Mazzoni A, et al. Substantivity of chlorhexidine to human dentin. Dent Mater. 2010;26:779-85 